\title{
Bcl-2 stabilization by paxillin confers 5-fluorouracil resistance in colorectal cancer
}

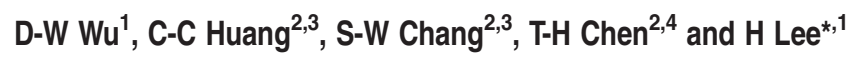

5-Fluorouracil (5-FU) is chemotherapeutic agent widely used for the treatment of colorectal cancer. Unfortunately, advanced colorectal cancer is often resistance to such chemotherapy and poor outcome. An adaptor protein paxillin (PXN) is phosphorylated at Y31/Y118 (pPXN-Y31/Y118) by Src contributes to cell mobility and Ser (S)272 of PXN in LD4 domain is important to the interaction between PXN and Bcl-2. We thus hypothesized that PPXN-Y31/Y118 may be required for Bcl-2 protein stability via PXN interacting with Bcl-2 to confer 5-FU resistance in colorectal cancer. Mechanistically, pPXN-S272 is phosphorylated through pPXN-Y31/Y118mediated p21 protein-activated kinase 1 (PAK1) activation and pPXN-S272 is required for PXN to interact with Bcl-2. The interaction between PXN and Bcl-2 is essential for Bcl-2 protein stability through phosphorylation of Bcl-2 at S87 (pBcl-2-S87) by pPXN-Y31/ Y118-mediated ERK activation. An increase in Bcl-2 expression by PXN is responsible for resistance to 5-FU. The resistance to 5-FU can be abolished by inhibitor of Src and PAK1 or Bcl-2 antagonist in cell and animal models. Among patients, Bcl-2 expression is positively correlated with expression of PXN and pPXN-S272, respectively. Patients with high PXN/high Bcl-2 or high pPXN-S272/high Bcl-2 tumors are commonly to have an unfavorable response to 5-FU-based chemotherapy, compared with patients who have high PXN, high pPXN-S272 or high Bcl-2 tumors alone. Therefore, we suggest that Src, PAK1 or Bcl-2 inhibitor may potentially overcome the resistance of 5 -FU-based chemotherapy and consequently to improve outcomes in patients with PXN/Bcl-2 and pPXN-S272/Bcl-2-positive tumors.

Cell Death and Differentiation (2015) 22, 779-789; doi:10.1038/cdd.2014.170; published online 17 October 2014

The incidence of colorectal cancer has markedly increased over the past two decades and became the third leading cancer death in Taiwan. ${ }^{1,2}$ Patients with colorectal cancer commonly receive 5-fluorouracil (5-FU)-based chemotherapy after surgical resection. ${ }^{3}$ The 5 -year survival of Dukes B patients is approximately $75 \%$, indicating that $\sim 25 \%$ of Dukes B patients may potentially benefit from adjuvant chemotherapy. ${ }^{4}$ However, the response rate of advancedstage patients to 5-FU-based chemotherapy was only $10-15 \% .^{5}$ Therefore, there is an urgent need to establish therapeutic biomarkers and available clinical approaches to improve the response of colorectal patients who received 5-FU-based chemotherapy.

Paxillin (PXN) has been shown to promote tumor aggressiveness, including that of colorectal cancer. ${ }^{6} \mathrm{~A}$ recent report indicated that PXN may promote cell proliferation in SW480 colon cancer cells and PXN expression was associated with overall survival (OS) but not related with $\mathrm{Bcl}-2$ in colorectal cancer patients. ${ }^{7}$ Our previous report indicated that phosphorylation of $\mathrm{PXN}$ at $\mathrm{Y} 31 / \mathrm{Y} 118$ (pPXN-Y31/Y118) by Src signaling pathway increased Bcl-2 expression at a transcriptional level in lung cancer cells via
ERK activation. ${ }^{8}$ Surprisingly, our preliminary data showed that PXN-mediated $\mathrm{Bcl}-2$ expression in colon cancer cells was predominately through a post-translational level, not through a transcriptional level. PXN has been reported to interact with Bcl-2 and S272 of PXN in LD4 domain is associated with PXN interaction with $\mathrm{Bcl}-2 .{ }^{9}$ The positive feedback activation loop of phosphorylation of PXN at Ser272 (pPXN-S272) and p21 protein-activated kinase 1 (PAK1) has been shown to regulate adhesion and protrusion dynamics. ${ }^{10}$ We thus hypothesized that $\mathrm{Bcl}-2$ protein stability by PXN overexpression could have a crucial role in the resistance to $5-\mathrm{FU}$ in colorectal cancer. To test the hypothesis, mechanistic studies were performed in cell and animal model to explore whether PXN-mediated Bcl-2 protein stability could confer 5-FU resistance via phosphorylation of PXN-S272 by PPXN-Y31/Y118-mediated PAK1 activation and phosphorylation of Bcl-2 at Ser87 (pBcl-2-S87) through pPXN-Y31/Y118-mediated ERK activation. Consequently, we expected that an increased $\mathrm{Bcl}-2$ by PXN overexpression may be associated with unfavorable response to 5-FU-based chemotherapy in patients with colorectal cancer.

\footnotetext{
${ }^{1}$ Graduate Institute of Cancer Biology and Drug Discovery, College of Medical Science and Technology, Taipei Medical University, Taipei, Taiwan; ${ }^{2}$ School of Medicine, College of Medicine, Chung Shan Medical University, Taichung, Taiwan; ${ }^{3}$ Division of Colon and Rectum, Department of Surgery, Chung Shan Medical University Hospital, Taichung, Taiwan and ${ }^{4}$ Division of Gastroenterology, Department of Internal Medicine, Chung Shan Medical University Hospital, Taichung, Taiwan

*Corresponding author: H Lee, Graduate Institute of Cancer Biology and Drug Discovery, Taipei Medical University, 5 Room, 12th Floor, No. 3, Park Street, Nangang District 115, Taipei, Taiwan. Tel: +886 227361771 \#7616; Fax: +886 22255 8562; E-mail: hl@tmu.edu.tw

Abbreviations: 5-FU, 5-fluorouracil; PXN, paxillin; PAK1, p21 protein-activated kinase 1; shRNA, small hairpin RNA; WT, wild type; NC, nonspecific shRNA control; VC, empty vector control; pPXN-Y31/Y118, phosphorylation of PXN at Tyr31/Tyr118; pPXN-S272, phosphorylation of PXN at Ser272; pBcl-2-S87, phosphorylation of Bcl-2 at Ser87; IP, immunoprecipitation; MTT, 3-(4,5-cimethylthiazol-2-yl)-2,5-diphenyl tetrazolium bromide; IC50, 50\% inhibition of the cell viability; PD, progressive disease; SD, stable disease; CR, complete response; PR, partial response; CSMUH, Chung Shan Medical University Hospital; IHC, immunohistochemistry; OS, overall survival Received 24.4.14; revised 25.8.14; accepted 12.9.14; Edited by JP Medema; published online 17.10.14
} 
a

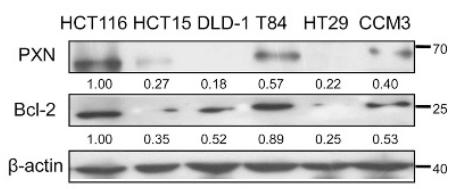

b
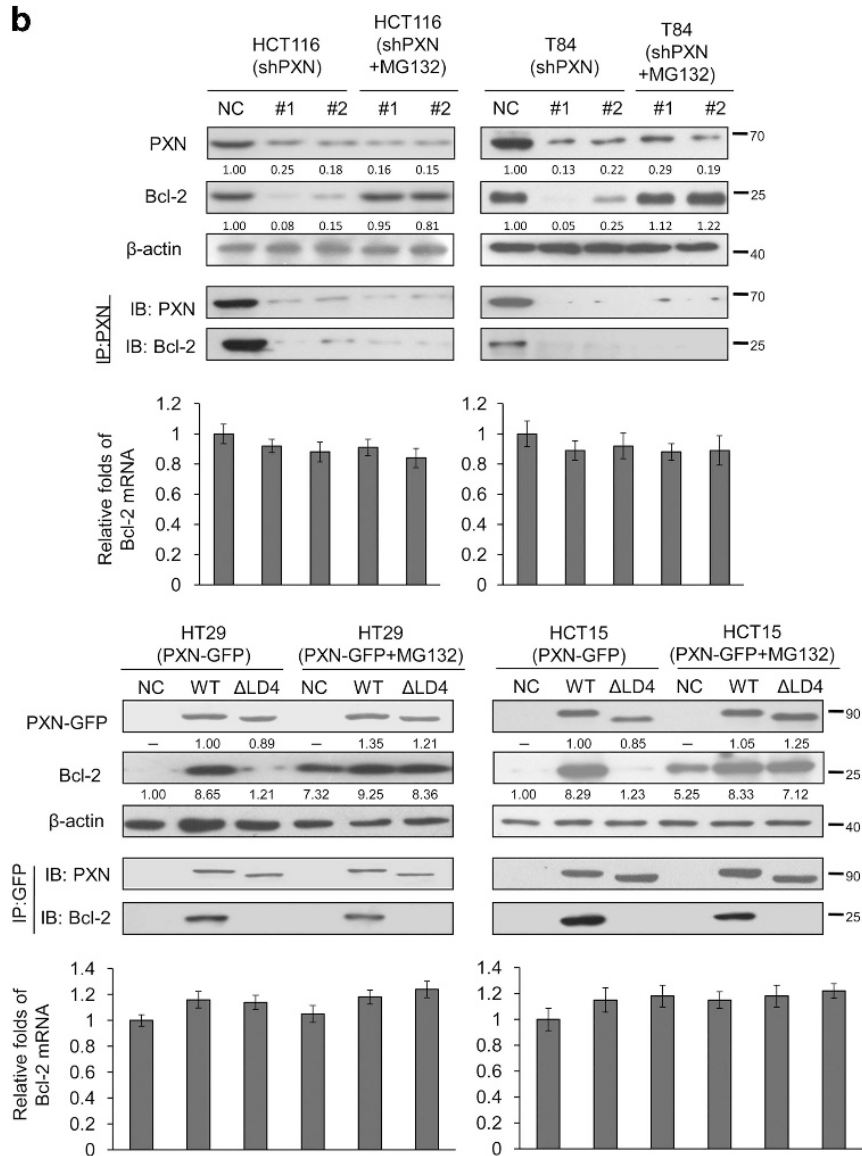

C

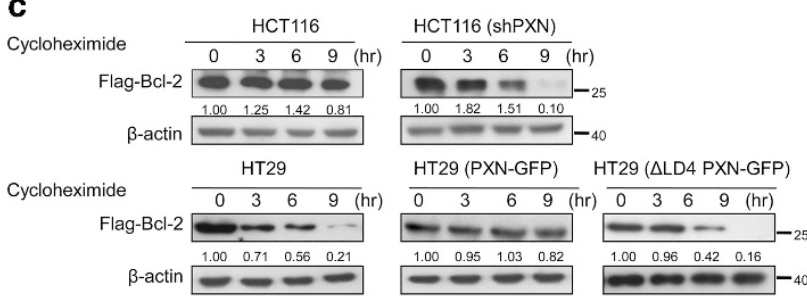

d
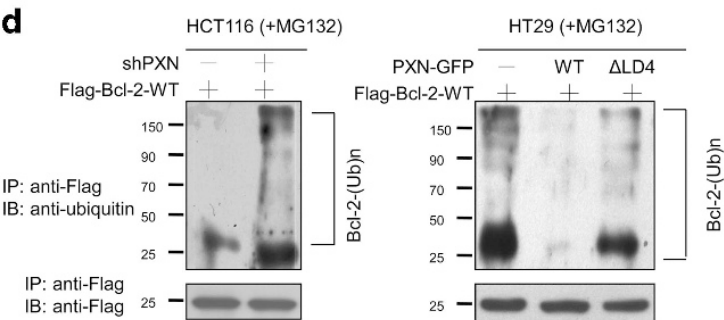

e
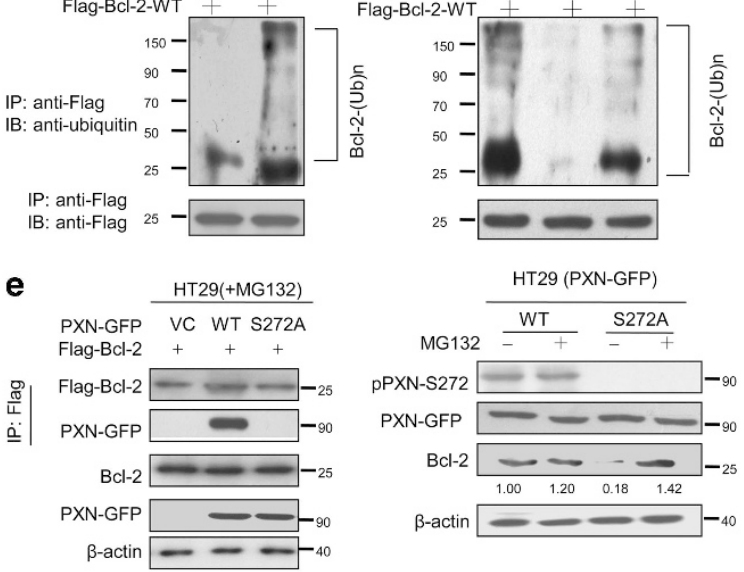

f
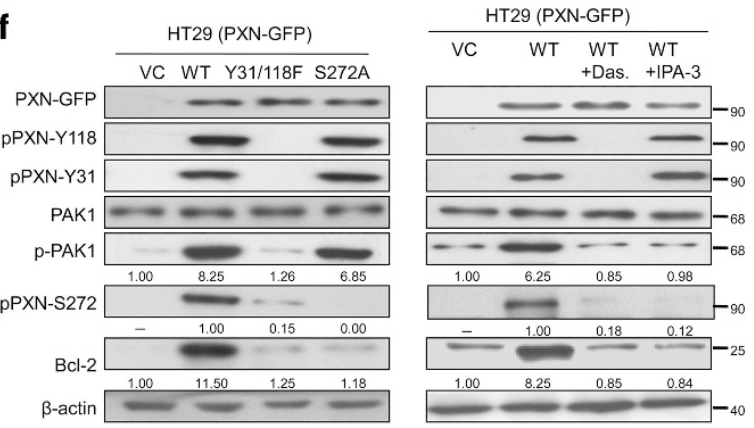

Figure 1 An increase in $\mathrm{Bcl}-2$ protein stability by PXN overexpression in colorectal cancer cells via increased PXN interaction with $\mathrm{Bcl}-2$. (a) PXN and Bcl-2 protein expression levels in a panel of colon cancer cells were determined by western blotting analysis. (b) HCT116 and T84 cells were transfected with two different PXN shRNAs. HT29 and HCT15 cells were transfected with WT PXN or mutant PXN- $\Delta$ LD4 and then these cells were treated with or without $5 \mu$ mol/l MG132 for additional $5 \mathrm{~h}$. These cells lysates were immunoprecipitated with anti-PXN or-GFP-conjugated beads. Immunoprecipitates were separated by SDS-PAGE for the evaluating Bcl-2 and PXN expression by western blotting using specific antibodies. All experiments were conducted three times independently and the relative mRNA level was indicated as the fold activation relative to the control cells. The S.D. was shown by error bars. P-value was obtained from Student's t-test. (c) HCT116 cells were co-transfected with the indicated combination of WT Bcl-2 and PXN shRNA for $24 \mathrm{~h}$. HT29 cells were co-transfected with the indicated combinations of WT Bcl-2, WT PXN or mutant PXN- $\Delta \mathrm{LD} 4$ for $24 \mathrm{~h}$ and then these cells were incubated with cycloheximide $(20 \mu \mathrm{g} / \mathrm{ml})$ at the indicated time points. These treatment cells were harvested and lysed to analyze Bcl-2 levels by an anti-Flag antibody. (d) HCT116 cells were cotransfected with the indicated combinations of WT Bcl-2 and PXN shRNA for $36 \mathrm{~h}$. HT29 cells were co-transfected with the indicated combinations of WT Bcl-2, WT PXN or mutant PXN- $\Delta$ LD4 for $36 \mathrm{~h}$ and then these cells were treated with MG132 for additional $5 \mathrm{~h}$. Cell lysates were immunoprecipitated with anti-Flag-conjugated beads. Immunoprecipitates were separated by SDS-PAGE for the evaluating ubiquitin pattern by western blotting using specific antibodies. (e) HT29 cells were co-transfected with the indicated combinations of WT Bcl-2, WT PXN or mutant PXN-S272A for $36 \mathrm{~h}$ and then treated with MG132 for additional $5 \mathrm{~h}$. Cells were lysed and the lysates were immunoprecipitated with anti-Flagconjugated beads. The HT29 cells were transfected with WT PXN or mutant PXN-S272A for $36 \mathrm{~h}$ and then treated with $5 \mu \mathrm{mol} / / \mathrm{MG} 132$ for additional $5 \mathrm{~h}$. The total lysates and immunoprecipitates were separated by SDS-PAGE for the evaluating PXN, Bcl-2 and pPXN-S272 expression by western blotting using specific antibodies. (f) The PXN was overexpressed, using WT PXN or mutant PXN-Y31/118F and -S272A in HT29 cells. PXN-overexpressing HT29 cells were treated with the inhibitor of Src (0.2 $\mu$ mol// Dasatinib) or PAK1 (10 $\mu$ mol// IPA-3) for $5 \mathrm{~h}$, and then these cells lysates were separated by SDS-PAGE for the evaluating PXN, Bcl-2 and pPXN-S272 expression by western blotting using specific antibodies

\section{Results}

The interaction between PXN and Bcl-2 increases Bcl-2 expression by protecting $\mathrm{Bcl}-2$ protein degraded by proteasomes. Western blotting analysis showed that PXN and Bcl-2 were concomitantly expressed in a panel of colon cancer cell lines. Among these cells, both proteins were expressed highly in HCT116 and T84 cells, but expressed lowly in HCT15 and HT29 cells (Figure 1a). HCT116, T84, HCT15 and HT29 cells transfected with two PXN small 
hairpin RNAs (shRNA) and a wild-type (WT) PXN-GFP expression vector to test whether PXN expression could modulate $\mathrm{Bcl}-2$ expression. As expected, PXN expression levels were decreased by PXN-knockdown in HCT116 and T84 cells and increased by PXN overexpression in HT29 and HCT15 cells (Figure 1b). Intriguingly, Bcl-2 expression was decreased markedly in PXN-knockdown HCT116 and T84 cells compared with their parental cells with nonspecific shRNA control transfection (NC). Conversely, Bcl-2 was more significantly increased in PXN-overexpressing HT29 and HCT15 cells than their parental cells with empty vector transfection (VC). Real-time RT-PCR analysis indicated that Bcl-2 mRNA expression levels were nearly unchanged by PXN manipulation in these colon cancer cells (Figure 1b). The change of $\mathrm{Bcl}-2$ protein expression by $\mathrm{PXN}$ manipulation was not correspondent with Bcl-2 mRNA levels in these cells (Figure $1 \mathrm{~b}$ ). These results suggest that the $\mathrm{Bcl}-2$ protein expression modulated by PXN may be through a posttranslational level but not through a transcriptional level. As shown in Figure 1b, the decrease of $\mathrm{Bcl}-2$ expression in PXN knockdown HCT116 and T84 cells was rescued by proteasomal inhibitor MG132 compared with PXN-knockdown HCT116 and T84 cells without MG132 treatment. Bcl-2 protein level decreased in HT29 and HCT15 cells with mutant PXN- $\triangle$ LD4 transfection compared with HT29 and HCT15 cells with WT PXN transfection (Figure 1b), but Bcl-2 level in HT29 and HCT15 cells with mutant PXN- $\triangle$ LD4 transfection was nearly rescued by MG132 treatment. Immunoprecipitation (IP) assay further showed that PXN interaction with $\mathrm{Bcl}-2$ was significantly decreased by PXN-knockdown in HCT116 and T84 cells, but markedly increased in WT PXNoverexpressing HT29 and HCT15 cells. However, an increase in the interaction between PXN and Bcl-2 did not observe in HT29 and HCT15 cells with mutant PXN-SLD4 transfection (Figure 1b). A pulse-chase experiment using a translation inhibitor cycloheximide was performed during 0 - to 9-h intervals. The half-life of $\mathrm{Bcl}-2$ expression was significantly reduced in PXN-knockdown HCT116 and T84 cells and elevated in PXN-overexpressing HT29 and HCT15 cells during the time intervals compared with their parental cells (Figure 1c and Supplementary Figure 1a). The ubiquitination pattern of $\mathrm{Bcl}-2$ protein in PXN-knockdown HCT116 and T84 cells was more extensive than in their vector control cells with MG132 treatment (Figure 1d and Supplementary Figure 1b). The ubiquitination pattern of Bcl-2 protein in vector control and mutant PXN- $\triangle \mathrm{LD} 4$-overexpressing HT29 and HCT115 cells was more extensive than in WT PXN-overexpressing cells with MG132 treatment (Figure 1d and Supplementary Figure $1 \mathrm{~b}$ ). These results suggest that the elevation of $\mathrm{Bcl}-2$ expression by PXN interaction with $\mathrm{Bcl}-2$ may be through protecting $\mathrm{Bcl}-2$ protein degradation by ubiquitin-proteasomal pathway.

Phosphorylation of PXN at $\mathbf{S 2 7 2}$ by PAK1 is required for PXN interaction with $\mathrm{Bcl}-2$ and $\mathrm{Bcl}-2$ protein stability. We examined whether pPXN-S272 could be required for PXN interaction with $\mathrm{Bcl}-2$ and, in turn, increase $\mathrm{Bcl}-2$ expression. HT29 and HCT15 cells were transfected with WT PXN and mutant PXN-S272A expression vector. IP analysis showed that the interaction between PXN and $\mathrm{Bcl}-2$ was seen in
HT29 and HCT15 cells with WT PXN transfection, but not observed in HT29 and HCT15 cells with mutant PXN-S272A transfection (Figure 1e and Supplementary Figure 1c left panel). However, Bcl-2 expression in HT29 and HCT15 cells with mutant PXN-S272A transfection can be rescued by MG132 treatment (Figure 1e and Supplementary Figure 1c right panel). We next tested whether PPXN-Y31/118 could be required for PAK1-mediated PXN phosphorylation at S272. ${ }^{8}$ Phosphorylated PAK1 (p-PAK1), pPXN-S272 and Bcl-2 were only observed in HT29 and HCT15 cells with WT PXN transfection, but not in HT29 and HCT15 cells with mutant PXN-Y31F/Y118F transfection (Figure $1 f$ and Supplementary Figure 1d left panel). The expression levels of pPXN-S272 and $\mathrm{Bcl}-2$ were decreased by mutant PXN-S272A transfection in HT29 and HCT15 cells, but p-PAK1 expression was not changed by PXN S272A transfection (Figure $1 \mathrm{f}$ and Supplementary Figure 1d left panel). Concomitant expression of p-PAK1, pPXN-S272 and Bcl-2 detected in HT29 and HCT15 cells with WT PXN transfection, but these expression levels were inhibited by Dasatinib or IPA-3 treatment (Figure $1 \mathrm{f}$ and Supplementary Figure 1d right panel). These results suggest that phosphorylation of PXN-S272 by PAK1 activation is mediated by $\mathrm{PPXN}-\mathrm{Y} 31 / \mathrm{Y} 118$, and $\mathrm{pPXN}-\mathrm{S} 272$ is required for interacting with $\mathrm{Bcl}-2$ and $\mathrm{Bcl}-2$ protein stability.

Phosphorylation of Bcl-2 at Ser 87 (pBcl-2-S87) has an important role in $\mathrm{Bcl}-2$ protein stability. ${ }^{11}$ As shown in Figure $2 \mathrm{a}$ and Supplementary Figure 2a (left panel), Bcl-2 and pBcl-2S87 were almost reduced by the PAK1 inhibitor - IPA-3 treatment in WT PXN-overexpressing HT29 and HCT15 cells; simultaneously, the interaction between PXN and Bcl-2 was not detected by IP analysis. The disappearance of $\mathrm{pBcl}-2-\mathrm{S} 87$ expression and $\mathrm{PXN}$ interaction with $\mathrm{Bcl}-2$ were also seen in HT29 and HCT15 cells with mutant PXN-S272A transfection. However, the decrease of Bcl-2 expression by IPA-3 in WT PXN-overexpressing HT29 and HCT15 cells, or the reduction of Bcl-2 expression in HT29 and HCT15 cells with mutant PXN-S272A transfection, can be rescued by MG132 treatment (Figure $2 \mathrm{a}$ and Supplementary Figure $2 \mathrm{a}$ right panel). However, the decrease of pBcl-2-S87 expression by IPA-3 in WT PXN-overexpressing HT29 and HCT15 cells, or the reduction of $\mathrm{Bcl}-2$ expression in HT29 and HCT15 cells with mutant PXN-S272A transfection, cannot be rescued by MG132 treatment. We next examined whether Bcl-2 phosphorylation and its expression could be regulated by $\mathrm{PPXN}-\mathrm{Y} 31 / \mathrm{Y} 118-$ mediated ERK activation. Western blotting showed that $\mathrm{Bcl}-2$ and phosphorylated ERK ( $p$-ERK) expression in HT29 and HCT15 cells with WT PXN transfection were significantly decreased by Src inhibitors (Dasatinib) and mutant PXN-Y31/118F transfection (Figure $2 \mathrm{~b}$ and Supplementary Figure 2b). In addition, Bcl-2 and pBcl-2-S87 expression in HCT116 and T84 cells were significantly decreased by ERK inhibitors (U0126 and AZD6244). However, although a decrease in Bcl-2 by ERK inhibitors can be rescued by MG132, the restoration of $\mathrm{pBcl}-2-\mathrm{S} 87$ by MG132 was not observed in HCT116 and T84 cells (Figure 2c and Supplementary Figure 2c upper panel). The decrease of Bcl-2 and $\mathrm{pBcl}-2-\mathrm{S} 87$ expression was also observed in PXNoverexpressing HT29 and HCT15 cells with ERK inhibitor treatments (Figure $2 \mathrm{c}$ and Supplementary Figure $2 \mathrm{c}$ lower panel). In the presence of MG132, a more extensive ubiquitin 
a

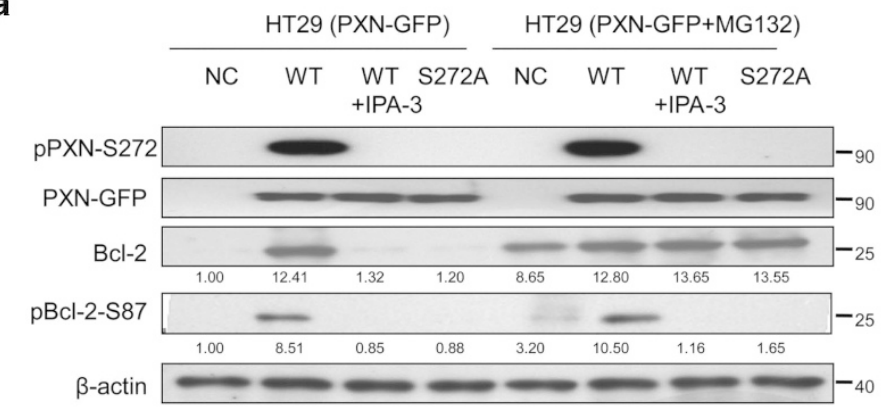

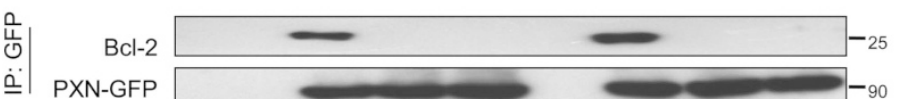

b

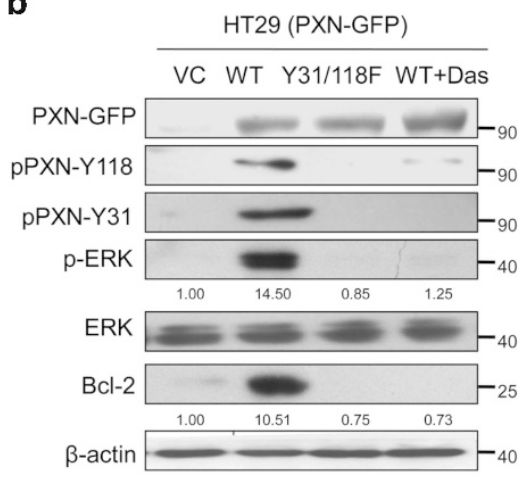

C

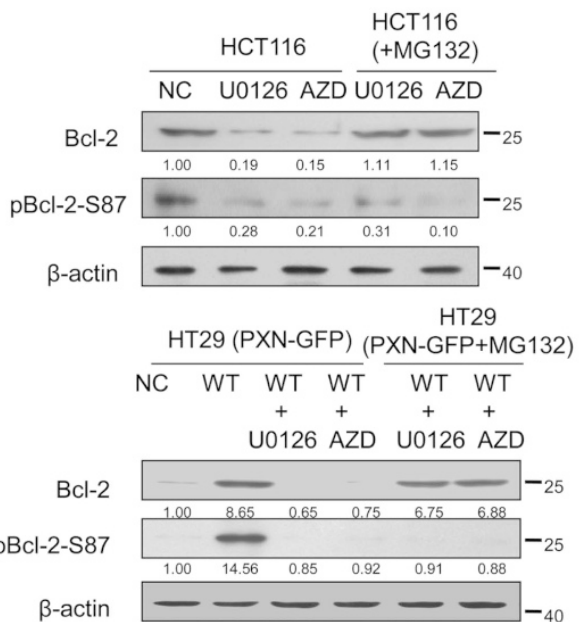

d
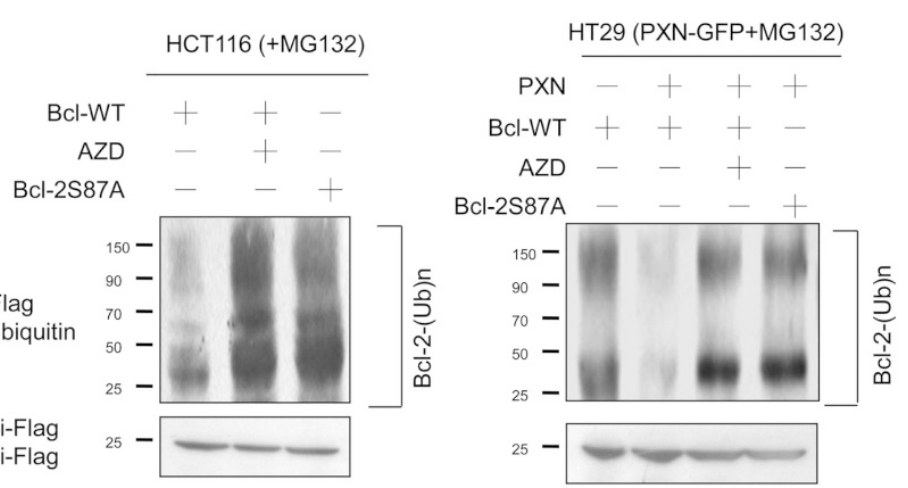

Figure 2 Phosphorylation of PXN-S272 is essential for an increase in phosphorylated Bcl-2-S87 via protecting Bcl-2 degradation by ubiquitin-proteasomes. (a) WT PXN or mutant PXN-S272A-overexpressing HT29 cells were treated with or without PAK1 inhibitor (10 $\mu$ mol/I IPA-3) for $5 \mathrm{~h}$ and then treated with or without MG132 for additional $5 \mathrm{~h}$. The cells were lysed and the lysates were immunoprecipitated with anti-GFP-conjugated beads. Total cell lysates and immunoprecipitates were separated by SDS-PAGE for evaluating pPXN-S272, PXN, Bcl-2 and pBcl-2-S87 expression by western blotting using specific antibodies. (b) HT29 cells were transfected with WT PXN or mutant $\mathrm{PXN}-\mathrm{Y} 31 / 118 \mathrm{~F}$ for $36 \mathrm{~h}$ and then treated with or without with $0.2 \mu \mathrm{mol} / /$ Dasatinib for additional $5 \mathrm{~h}$. The cells lysates were separated by SDS-PAGE for the evaluating PXN, pPXNY31, pPXN-Y118, ERK, p-ERK and Bcl-2 expression by western blotting using specific antibodies. (c) HCT116 and PXN-overexpressing HT29 cells were treated with two kinds of ERK inhibitors $(10 \mu \mathrm{mol} / / \mathrm{U} 0126$ or $5 \mu \mathrm{mol} / / \mathrm{AZD} 6244, \mathrm{AZD})$ for $5 \mathrm{~h}$. These cells were treated with or without MG132, and then cells were lysed. The cell lysates were separated by SDS-PAGE for evaluating Bcl-2 and pBcl-2-S87 expression by western blotting using specific antibodies. (d) HCT116 cells were transfected with WT Bcl-2 or mutant Bcl-2S87A and then treated with or without $5 \mu \mathrm{mol} / / \mathrm{AZD}$, for additional $5 \mathrm{~h}$. $\mathrm{HT} 29 \mathrm{cells} \mathrm{Bcl-2}$ or mutant Bcl-2-S87A and then treated with or without $5 \mu \mathrm{mol} / / \mathrm{AZD}$ for additional $5 \mathrm{~h}$. After $41 \mathrm{~h}$, these cells were treated with MG132 for $5 \mathrm{~h}$. Cell lysates were immunoprecipitated with anti-Flag-conjugated beads. Immunoprecipitates were separated by SDS-PAGE for evaluating ubiquitin pattern by western blotting using specific antibodies

pattern of Bcl-2 was revealed in HCT116 and T84 cells with AZD6244 treatment or mutant Bcl-2 S87A transfection, compared with HCT116 and T84 cells with WT Bcl-2 transfection. A similar mechanistic action for Bcl-2 protein stability was also seen in PXN-overexpressing HT29 and HCT15 cells (Figure 2d and Supplementary Figure 2d). These results clearly indicate that $\mathrm{PPXN}-\mathrm{Y} 31 / \mathrm{Y} 118$ may be responsible for phosphorylation of PAK1 and PXN at S272. The pPXN-S272 has a critical role in an increased pBcl-2-S87 via protecting $\mathrm{Bcl}-2$ degradation by ubiquitin-proteasomes because of PXN interaction with $\mathrm{Bcl}-2$.

PXN-mediated $\mathrm{Bcl}-2$ expression is responsible for the resistance to 5-FU in colon cancer cells. We explored the possibility that apoptosis induced by 5 -FU could be associated with PXN-mediated $\mathrm{Bcl}-2$ expression. PXN expression in HCT116 and HT29 cells were depleted/ectopically expressed by shPXN or PXN-GFP transfection. MTT (3(4,5-cimethylthiazol-2-yl)-2,5-diphenyl tetrazolium bromide) assay showed that the inhibition concentration of 5-FU to $50 \%$ inhibition of the cell viability (IC50) were significantly decreased by PXN-knockdown when compared with NC cells $(7.5 \mu \mathrm{M}, 6.5 \mu \mathrm{M}$ versus $26.9 \mu \mathrm{M}$; Figure 3a left panel). Conversely, the IC50 value increased dose dependently in PXN-overexpressing HT29 cells when compared with VC cells $(18.2 \mu \mathrm{M}, 26.5 \mu \mathrm{M}$ versus $7.0 \mu \mathrm{M}$; Figure 3 a right panel). The percentage of apoptotic cells was increased and decreased in PXN-knockdown HCT116 and PXNoverexpressing HT29 cells (Figure 3b). Moreover, the percentage of apoptotic cells was increased by mutant PXN-Y31/Y118F or -S272A transfection and Src inhibitor (Dasatinib) or PAK1 inhibitor (IPA-3) treatment as compared with WT PXN transfection (Figure 3c). These results indicate that phosphorylation of PXN at S272 by PAK1 is responsible 
a
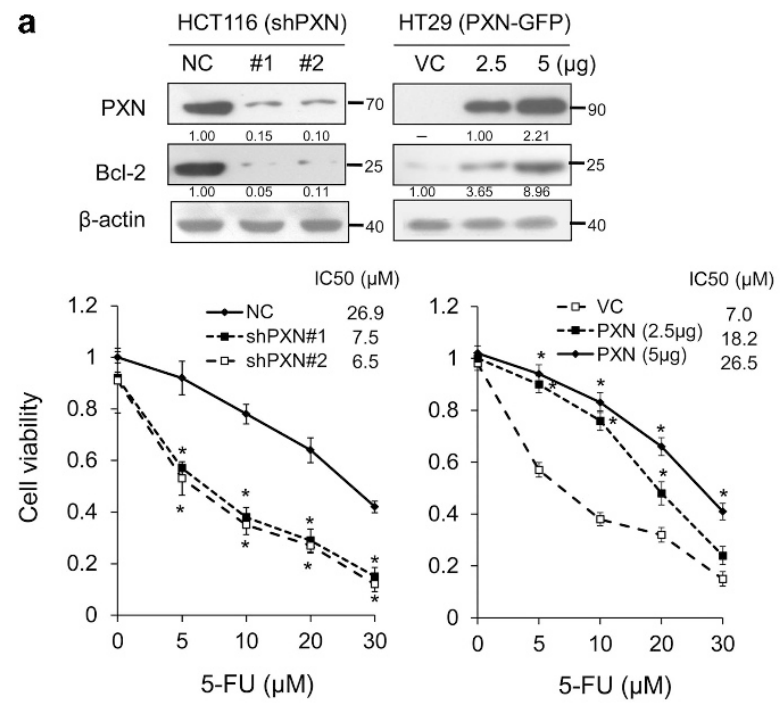

b

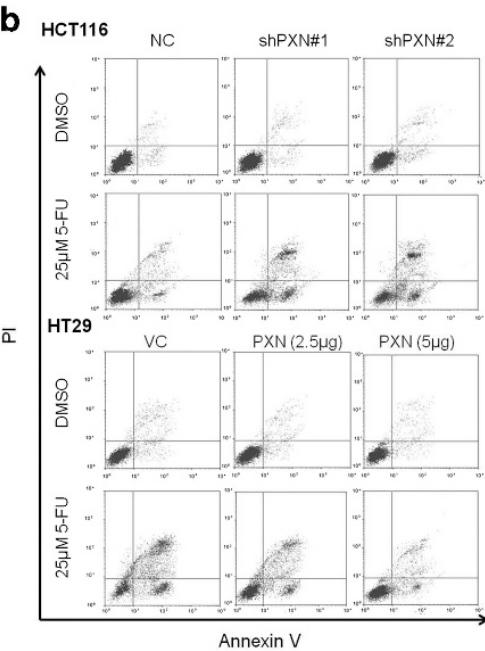

HCT116 (shPXN)
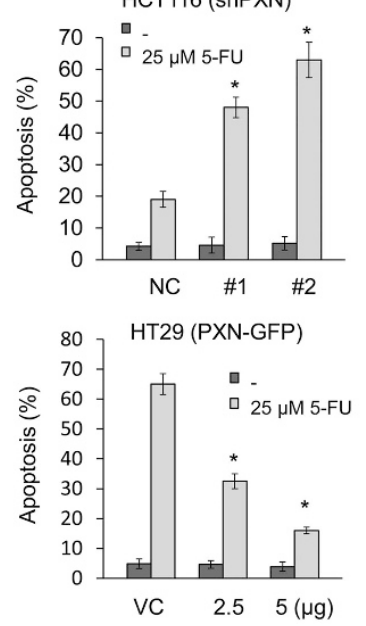

C

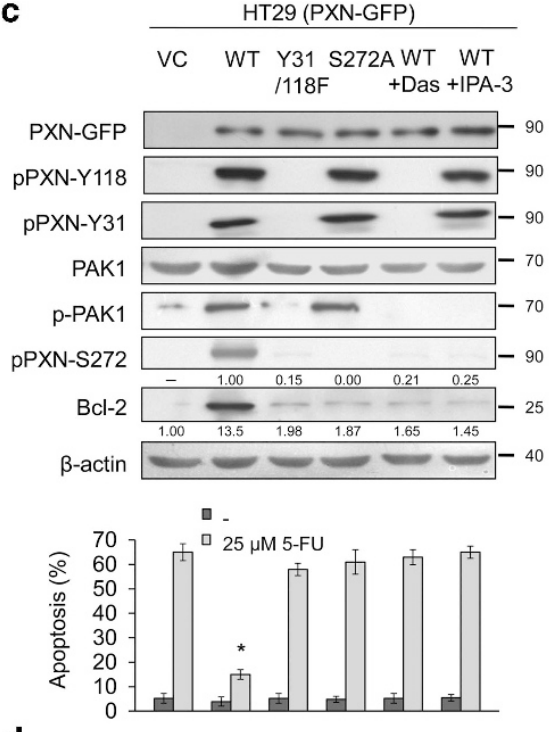

d

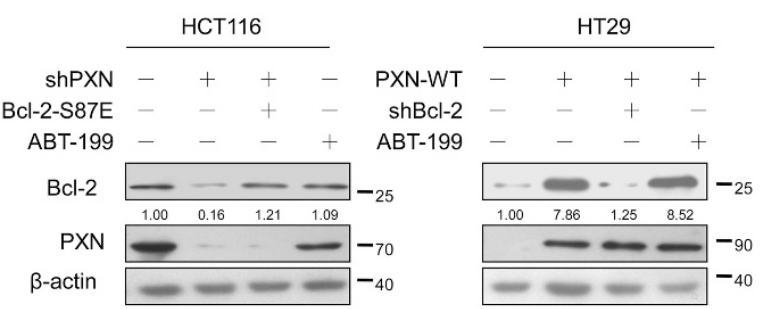

a.
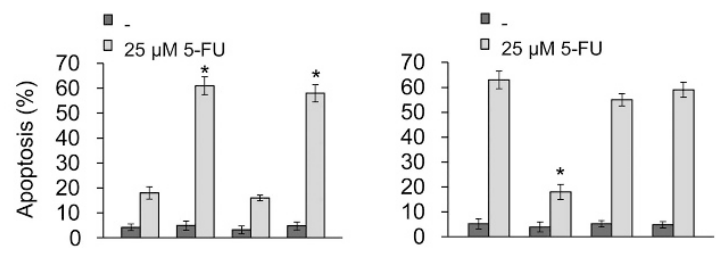

Figure 3 An increase in Bcl-2 expression by PXN overexpression is responsible for 5-FU resistance in colon cancer cells. (a) Two different PXN-knockdown plasmids were transfected into high PXN-expressing HCT116 cells for $24 \mathrm{~h}$. Alternatively, increasing amounts of PXN expression plasmid were transfected into low PXN-expressing HT29 cells for $24 \mathrm{~h}$. PXN-knockdown HCT116 or PXN-overexpressing HT29 cells were treated with various doses of 5-FU and the dose-response curves were used to calculate IC50. (b) PXN-knockdown HCT116 or PXN-overexpressing HT29 cells were treated with or without 5-FU for additional $48 \mathrm{~h}$ and the indicated cells were harvested and evaluated for apoptosis after Annexin- $\mathrm{V}$ and PI staining. The representative figure of indicated cells was shown (left panel). The percentage of apoptotic cells was determined by a flow cytometry analysis. (c) HT29 cells were transfected with WT PXN or mutant PXN-Y31/118F or -S272A. PXN-overexpressing HT29 cells were treated with or without inhibitor of Src (Dasatinib, Das) or PAK1 (IPA-3) for $5 \mathrm{~h}$. The indicated cells were treated with $0.1 \%$ DMSO or $25 \mu \mathrm{M} 5$-FU for additional $48 \mathrm{~h}$ to evaluate the percentage of apoptotic cells by a flow cytometry analysis. (d) HCT116 cells were co-transfected with the indicated combinations of shPXN, mutant Bcl-2-S87E and then treated with or without $0.01 \mathrm{nmol} / \mathrm{ABT}-199$ for $5 \mathrm{~h}$. HT29 cells were co-transfected with WT PXN, shBcl-2 and then treated with or without $0.01 \mathrm{nmol} / \mathrm{ABT}-199$. These cells were treated with $0.1 \%$ DMSO or $25 \mu \mathrm{M} 5$-FU for additional $48 \mathrm{~h}$ to evaluate the percentage of apoptotic cells by a flow cytometry analysis. All experiments were performed three times independently and the relative cell viability was indicated as the fold-activation relative to the control cells. The relative cell viability of the NC cells was arbitrarily assigned as 1 and the S.D. was shown by error bars. The mean percentage of cell apoptosis was calculated and the S.D. was shown by error bars. $P$-value was obtained from Student's $t$-test. ${ }^{*} P<0.05$ was relative to the control cells with vector (VC) or NC plasmids

for Bcl-2 protein stability and, in turn, confers 5-FU resistance. PXN-knockdown HCT116 and PXN-overexpressing HT29 cells were further ectopically expressed and silenced Bcl-2 or direct treatment of Bcl-2 inhibitor ABT-199 to clarify whether $\mathrm{PXN}$-mediated $\mathrm{Bcl}-2$ could be responsible for 5 -FU resistance. Bcl-2 expression was decreased and increased in PXN-knockdown HCT116 and PXN-overexpressing HT29 cells, but Bcl-2 expression was restored by Bcl-2 ectopic expression in PXN-knockdown HCT116 cells and was decreased by $\mathrm{Bcl}-2$ silencing in PXN-overexpressing HT29 cells (Figure $3 d$ upper panel). Interestingly, the percentage of apoptotic cells induced by $5-\mathrm{FU}$ treatment was rescued by ectopically expressing mimic phosphorylation of mutant Bcl2-S87E in PXN-knockdown HCT116 cells when compared with NC cells (Figure 3d left panel). In addition, the percentage of apoptotic cells induced by 5-FU treatment was significantly increased by Bcl-2 inhibitor ABT-199 in HCT116 NC cells when compared with HCT116 NC cells without ABT-199 treatment (Figure 3d left panel). The same phenomenon was seen in PXN-overexpressing HT29 cells with Bcl-2 silencing or ABT-119 treatment (Figure 3d right panel). In addition, a similar mechanistic action of PXN on 
5-FU resistance was also demonstrated in T84 and HCT115 cells (Supplementary Figure 3). 5-FU combined with oxaliplatin is frequently used for chemotherapeutics in patients with colorectal cancer. ${ }^{12}$ The same mechanism of PXNmediated oxaliplatin resistance compared with 5-FU resistance was further evidenced in these colon cancer cells

a
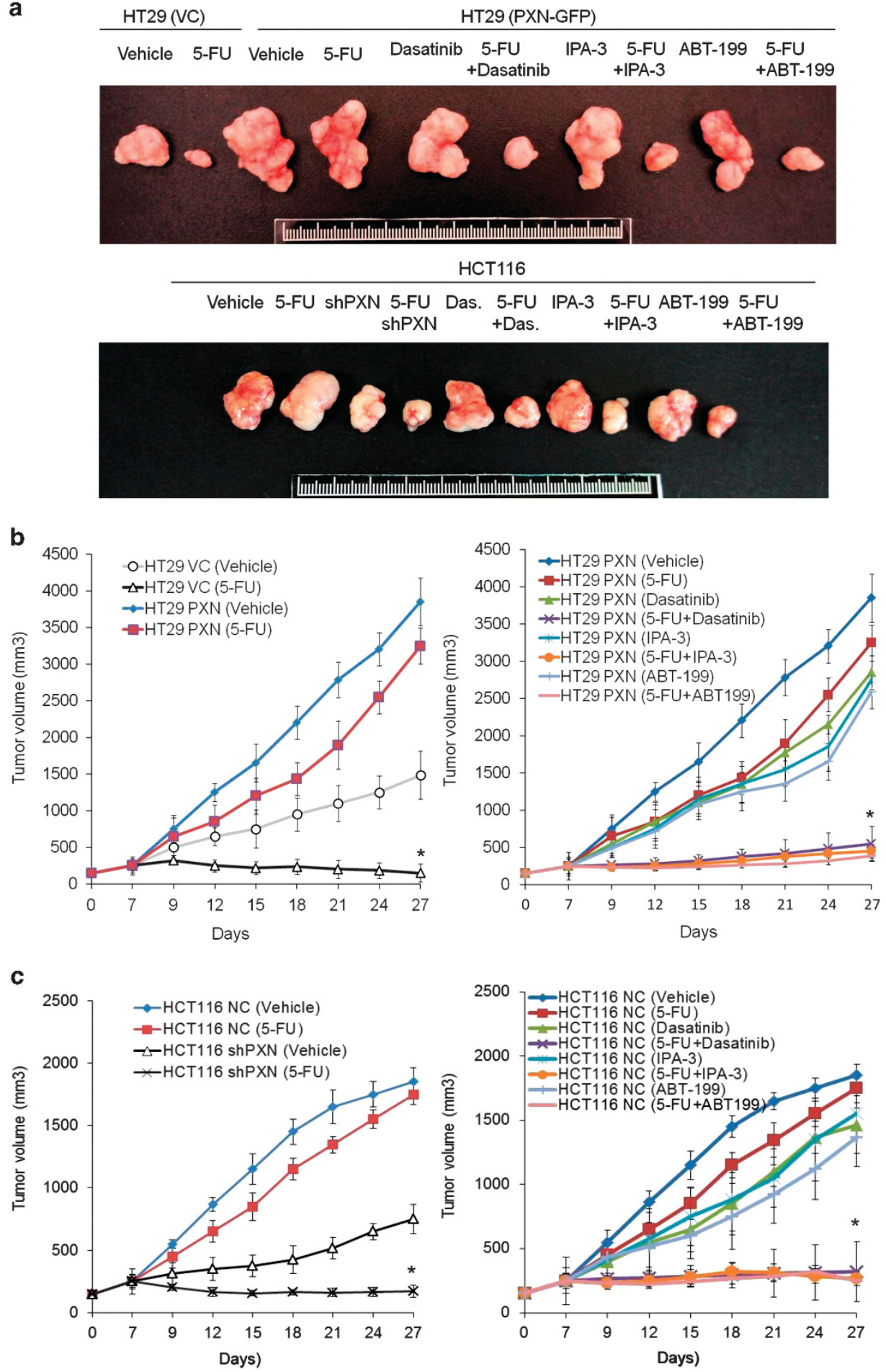

Figure 4 PXN-mediated xenograft tumors were more effectively suppressed by 5-FU combined with Dasatinib, IPA-3 or ABT-199. (a) HT29 VC and HCT116 shPXN xenografts were treated with vehicle and 5-FU (5 mg/kg). HT29 PXN and HCT116 NC xenografts were treated with vehicle, $5-\mathrm{FU}(5 \mathrm{mg} / \mathrm{kg})$, Dasatinib (5 mg/kg), IPA-3 (5 mg/kg), ABT-199 (5 mg/kg), singly or a combination of both. The representative tumor burdens in the 10 groups are shown. (b) Tumor volumes of HT29 cells in the nude mice of the 10 groups were measured at 3-day intervals from days 9 to days 27. (c) Tumor volumes of HCT116 cells in the nude mice of the 10 groups were measured at 3-day intervals from days 9 to days 27 . Mean \pm S.E.M values $\left(\mathrm{mm}^{3}\right)$ were calculated from the tumor volume of five nude mice in each group. $P$-value was obtained from Student's $t$-test. ${ }^{*} P<0.05$ was relative to the control cells with vector (VC) or NC plasmids 
(Supplementary Figure 4). These results clearly indicate that PXN-mediated Bcl-2 expression is responsible for 5-FU/ oxaliplatin resistance in colon cancer cells.

PXN-mediated xenograft tumors were more effectively suppressed by 5-FU combined with Dasatinib, IPA-3 or ABT-199. As previously described, we expected that PXNmediated 5-FU resistance can be conquered by inhibitor of Src and PAK1 or Bcl-2 antagonist via decreased $\mathrm{Bcl}-2$ expression. The representative xenograft tumors in each group of nude mice were shown in Figure 4a. The tumor volume in nude mice with HT29 VC cell injection grew slowly during 7 to 27 days. The tumor volume of nude mice injected with HT29 VC cells can be suppressed by 5-FU treatment (VC versus VC+5-FU; Figure 4b). However, the tumor volume of nude mice injected with PXN-overexpressing HT29 cells increased markedly during the time intervals, but the tumor volume of nude mice injected with PXN-overexpressing HT29 cells was almost unchanged by $5-\mathrm{FU}$ treatment (PXN versus $\mathrm{PXN}+5-\mathrm{FU}$; Figure 4b). The tumor volume of nude mice injected with PXN-overexpressing HT29 cells was decreased markedly by 5-FU plus Src inhibitor (Dasatinib) or PAK1 inhibitor (IPA-3) or Bcl-2 inhibitor (ABT-199) ${ }^{13}$ when compared with nude mice injected with PXN-overexpressing HT29 cells, which were treated with 5-FU, Dasatinib, IPA-3 or ABT-199 alone (Figure 4b). A higher PXN-expressing HCT116 cells were further used to demonstrate that native PXN expression could confer 5-FU resistance in the nude mice. In addition, native $\mathrm{PXN}$-mediated 5-FU resistance occurred in nude mice injected with HCT116 cells can be overcome by Dasatinib, IPA-3 or ABT-199 (Figures 4a and c). These results obtained from PXN-overexpressing HT29- or HCT116-induced xenograft tumors in nude mice strongly support the findings in the cell model.

The levels of Bcl-2, PXN, pPXN-Y118, pPXN-S272 and cleavage caspase 3 in tumors of each group mice were evaluated by immunohistochemistry (IHC) to understand whether 5-FU-induced apoptotic and $\mathrm{PXN} / \mathrm{Bcl}-2$ pathway could be modulated by the inhibitors of Dasatinib and IPA-3 or Bcl-2 antagonist (ABT-199). The levels of Bcl-2 in tumors of nude mice injected with PXN-overexpressing HT29 or HCT116 cells in the presence or absence of 5-FU treatment were markedly reduced by Dasatinib and IPA-3, but not reduced by ABT-199 treatment (Supplementary Figure 5). Cleavage caspase 3 expression was significantly revealed in PXN-overexpressing HT29 and HCT116-injected nude mice with 5-FU plus Dasatinib or IPA-3 or ABT-199 treatment, but the elevation of caspase 3 did not change in these mice without 5-FU treatment (Supplementary Figure 5). In addition, $\mathrm{Bcl}-2$ expression in tumors of nude mice injected with PXNoverexpressing HT29 or HCT116 cells was concomitantly decreased with phosphorylated PXN at Y118 and S272 expression (Supplementary Figure 5). These results from the nude mice model strongly support the findings from the cell model, showing that PPXN-Y31/Y118-mediated PAK1 and ERK activation promotes $\mathrm{Bcl}-2$ protein stability via phosphorylation of PXN at S272 and Bcl-2 at S87 due to increased PXN interaction with $\mathrm{Bcl}-2$.

PXN, pPXN-S272 and Bcl-2 expression are associated with an unfavorable response to 5-FU-based chemotherapy in colorectal cancer patients. We expected that the coexistence of PXN or pPXN-S272 and Bcl-2 could be associated with an unfavorable response to 5-FU-based chemotherapy in colorectal cancer patients. To test the possibility, 99 patients who received 5-FU-based chemotherapy were enrolled to assess chemotherapeutic response. The representative immunostaining results of PXN, pPXNS272 and Bcl-2 in colorectal tumors are shown in Figure 5. Immunohistochemical data showed that high PXN and pPXN-S272 expression was seen more frequently in Duke $\mathrm{C}$ and Duke $\mathrm{D}$ tumors than in Duke $\mathrm{A}$ and Duke $\mathrm{B}$ tumors $(P<0.001)$, but the correlation was not observed between Dukes and $\mathrm{Bcl}-2$ expression (Table 1). In addition, PXN and

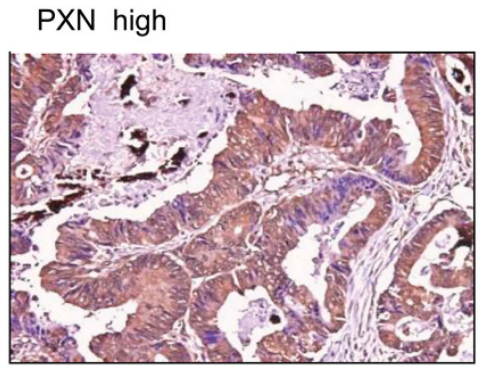

PXN low

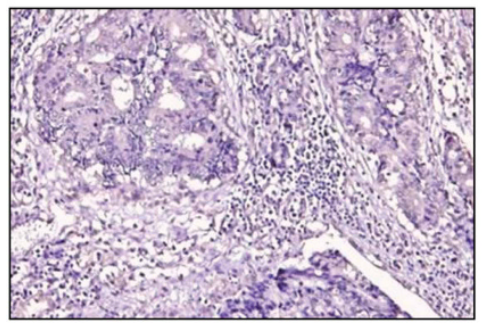

pPXN -S272 high

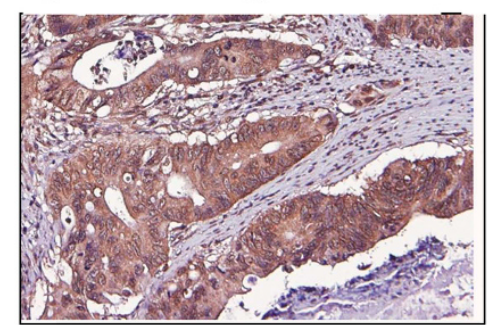

pPXN -S272 low

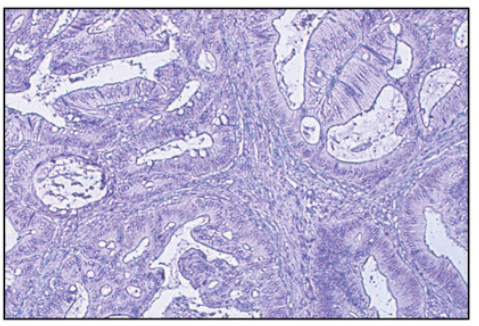

Bcl-2 high

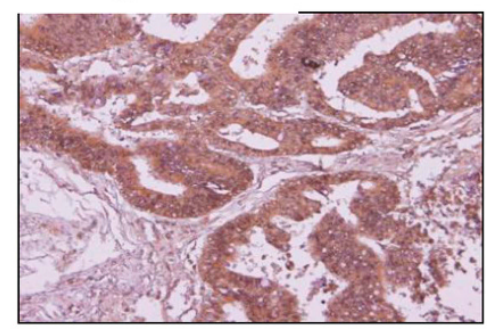

$\mathrm{Bcl}-2$ low

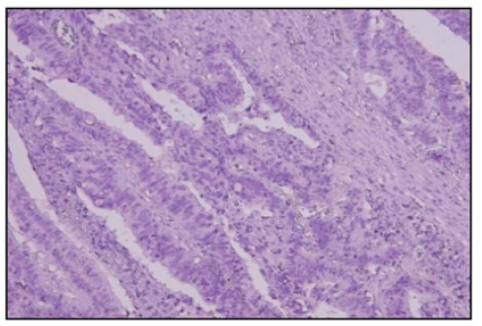

Figure 5 PXN, pPXN-S272 and Bcl-2 expression are associated with an unfavorable response to 5-FU-based chemotherapy in colorectal cancer patients. A representative figure of high or low of PXN, pPXN-S272, and Bcl-2 expression in colorectal cancer patients 
Table 1 The correlation between clinical parameters with PXN, pPXN-S272 and Bcl-2 expression levels in patients with colorectal cancer

\begin{tabular}{|c|c|c|c|c|c|c|c|c|c|c|}
\hline & \multirow[t]{2}{*}{ No } & \multicolumn{2}{|c|}{ PXN } & \multirow[t]{2}{*}{$P$-value } & \multicolumn{2}{|c|}{ pPXN-S272 } & \multirow[t]{2}{*}{$P$-value } & \multicolumn{2}{|c|}{ Bcl-2 } & \multirow[t]{2}{*}{$P$-value } \\
\hline & & Low & High & & Low & High & & Low & High & \\
\hline \multicolumn{11}{|l|}{ Age } \\
\hline $\begin{array}{l}<66 \\
\geqq 66\end{array}$ & $\begin{array}{l}57 \\
42\end{array}$ & $\begin{array}{l}34(60) \\
21(50)\end{array}$ & $\begin{array}{l}23(40) \\
21(50)\end{array}$ & 0.340 & $\begin{array}{l}39(68) \\
24(57)\end{array}$ & $\begin{array}{l}18(32) \\
18(43)\end{array}$ & 0.249 & $\begin{array}{l}30(53) \\
28(67)\end{array}$ & $\begin{array}{l}27(47) \\
14(33)\end{array}$ & 0.161 \\
\hline \multicolumn{11}{|l|}{ Gender } \\
\hline $\begin{array}{l}\text { Female } \\
\text { Male }\end{array}$ & $\begin{array}{l}50 \\
49\end{array}$ & $\begin{array}{l}24(48) \\
31(63)\end{array}$ & $\begin{array}{l}26(52) \\
18(37)\end{array}$ & 0.126 & $\begin{array}{l}29(58) \\
34(69)\end{array}$ & $\begin{array}{l}21(42) \\
15(31)\end{array}$ & 0.239 & $\begin{array}{l}26(52) \\
32(65)\end{array}$ & $\begin{array}{l}24(48) \\
17(35)\end{array}$ & 0.179 \\
\hline \multicolumn{11}{|l|}{ Smoking status } \\
\hline $\begin{array}{l}\text { Nonsmokers } \\
\text { Smokers }\end{array}$ & $\begin{array}{l}71 \\
28\end{array}$ & $\begin{array}{l}74(54) \\
21(75)\end{array}$ & $\begin{array}{r}64(46) \\
7(25)\end{array}$ & 0.014 & $\begin{array}{l}41(58) \\
22(79)\end{array}$ & $\begin{array}{r}30(42) \\
6(21)\end{array}$ & 0.052 & $\begin{array}{l}39(55) \\
19(68)\end{array}$ & $\begin{array}{r}32(45) \\
9(32)\end{array}$ & 0.240 \\
\hline \multicolumn{11}{|l|}{ Duke } \\
\hline $\begin{array}{l}A, B \\
C, D\end{array}$ & $\begin{array}{l}35 \\
64\end{array}$ & $\begin{array}{l}27(77) \\
28(44)\end{array}$ & $\begin{array}{r}8(23) \\
36(56)\end{array}$ & $<0.001$ & $\begin{array}{l}31(89) \\
32(50)\end{array}$ & $\begin{array}{r}4(11) \\
32(50)\end{array}$ & $<0.001$ & $\begin{array}{l}23(66) \\
35(55)\end{array}$ & $\begin{array}{l}12(34) \\
29(45)\end{array}$ & 0.287 \\
\hline \multicolumn{11}{|l|}{$P X N$} \\
\hline $\begin{array}{l}\text { Low } \\
\text { High }\end{array}$ & $\begin{array}{l}55 \\
44\end{array}$ & & & & $\begin{array}{c}55(100) \\
8(18)\end{array}$ & $\begin{array}{c}0(0) \\
36(82)\end{array}$ & $<0.001$ & $\begin{array}{l}39(71) \\
19(43)\end{array}$ & $\begin{array}{l}16(29) \\
25(57)\end{array}$ & 0.005 \\
\hline \multicolumn{11}{|l|}{$p P X N-S 272$} \\
\hline $\begin{array}{l}\text { Low } \\
\text { High }\end{array}$ & $\begin{array}{l}63 \\
36\end{array}$ & & & & & & & $\begin{array}{l}43(68) \\
15(42)\end{array}$ & $\begin{array}{l}20(32) \\
21(58)\end{array}$ & 0.010 \\
\hline
\end{tabular}

pPXN-S272 were not associated with other clinical parameters that include age, gender and smoking status. Surprisingly, PXN, pPXN-S272 or Bcl-2 expression was positively correlated with each other in the study population (Table 1). Patients with high PXN or with high Bcl-2 tumors were more commonly shown to have an unfavorable response to 5-FU-based chemotherapy (progressive disease, $\mathrm{PD}$ and stable disease, SD). Conversely, a favorable response (complete response, $\mathrm{CR}$ and partial response, $\mathrm{PR}$ ) to 5-FU-based chemotherapy was a more prevalent occurrence in patients with low PXN, low pPXN-S272 or low Bcl-2 tumors ( $P=0.001$ for PXN; $P<0.001$ for Bcl-2; Table 2). Notably, patients with high $\mathrm{PXN} /$ high $\mathrm{Bcl}-2$ or high $\mathrm{pPXN}$ S272/high Bcl-2 tumors were the most common to have unfavorable responses among the four subgroups $(60 \%$ versus $19 \%$ versus $11 \%$ versus $8 \%, P<0.001$; Table 2 ). These results reveal that patients with high PXN, high pPXNS272 or high Bcl-2 tumors may be more frequently to have unfavorable responses to 5-FU-based chemotherapy, especially in patients with high $\mathrm{PXN} /$ high $\mathrm{Bcl}-2$ or $\mathrm{pPXN}-\mathrm{S} 272 /$ high Bcl-2 tumors.

\section{Discussion}

Cancer death is determined by resistance to drugs and tumor relapse. Bcl-2 family proteins include Bcl-2, Bcl-xL and $\mathrm{Mcl}-1$, all of which are shown to protect cell apoptosis and, in turn, enhance drug resistance. ${ }^{14-17} \mathrm{Bcl}-2$ is an antiapoptotic gene involved in an evolutionarily conserved intrinsic apoptosis pathway. ${ }^{18}$ It acts by blocking the release of cytochrome c from mitochondria and inhibiting the activation of caspase 9 and caspase $3 .^{18}$ Our data showed that Bcl-w, Mcl-1 and IAPs were not changed by PXN-knockdown and PXN overexpression in HCT116 and HT29 cells, with the exception of Bcl-xL (Supplementary Figure 6a). However, the percentage of apoptotic cells was markedly increased by Bcl-2-knockdown in PXN-overexpressing HT29 cells, but the increase of apoptotic percentage by $\mathrm{Bcl}-\mathrm{xL}-\mathrm{knockdown}$ was relatively lower than that of $\mathrm{Bcl}-2-k n o c k d o w n$ in $\mathrm{PXN}$-overexpressing HT29 cells (Supplementary Figure 6b) These results suggest that $\mathrm{Bcl}-2$ may have a more important role in $\mathrm{PXN}$-mediated $5-\mathrm{FU}$ resistance in colorectal cancer cells as compared with $\mathrm{BCl}-\mathrm{xL}$.

The positive correlation of PXN with $\mathrm{Bcl}-2$ expression was observed in six cell lines except DLD1 cells (Figure 1a). K-ras and BRAF mutations were linked with activation of AKT and ERK signaling pathway. ${ }^{19-24}$ Therefore, the involvement of AKT and ERK activation in the increase of $\mathrm{Bcl}-2$ expression can be expected in colorectal cancer. All cell lines used in this study harbored either K-ras mutation or BRAF mutation (Supplementary Figure 7a). AKT and ERK activation were indeed observed in K-ras mutated DLD1 cells. ${ }^{25-27}$ Our data showed that $\mathrm{Bcl}-2$ expression in DLD1 cells was nearly diminished by AKT or ERK inhibitor (Supplementary Figure 7b). Therefore, Bcl-2 expression in DLD1 cells may be through the activation of ERK and AKT signaling pathway. Bcl-2 expression was increased markedly by PXN overexpression in DLD1 cells (Supplementary Figure 7c). Moreover, the similar mechanism of PXN-mediated Bcl-2 elevation because of increased $\mathrm{Bcl}-2$ protein stability was demonstrated in PXN-overexpressing DLD1 cells (Supplementary Figure 7c). Intriguingly, the increase of $\mathrm{Bcl}-2$ by $\mathrm{PXN}$ overexpression because of increased protein stability was also shown in WT K-ras/BRAF SW48 cells (Supplementary Figure 7c). Therefore, we suggest that the increased $\mathrm{Bcl}-2$ expression by AKT/ERK activation is not only through K-ras/BRAF mutation but also through PXN overexpression in colon cancer cells.

The prognostic value of $\mathrm{Bcl}-2$ in colorectal cancers is controversial. $^{28-31}$ For example, Bcl-2 expression was associated with favorable outcome in stage II colon cancer. ${ }^{31}$ 
Table 2 The correlation between chemotherapeutic response with PXN, pPXN$\mathrm{S} 272$ and $\mathrm{Bcl}-2$ expression levels in chemotherapeutic group of patients with colorectal cancer

\begin{tabular}{|c|c|c|c|c|}
\hline & \multirow[t]{2}{*}{ No. } & \multicolumn{2}{|c|}{$\begin{array}{l}\text { Chemotherapeutic } \\
\text { response }\end{array}$} & \multirow[t]{2}{*}{$P$-value } \\
\hline & & Unfavorable & Favorable & \\
\hline \multicolumn{5}{|l|}{$P X N$} \\
\hline Low & 55 & $6(11)$ & 49 (89) & 0.001 \\
\hline High & 44 & $17(43)$ & $27(61)$ & \\
\hline \multicolumn{5}{|l|}{$p P X N-S 272$} \\
\hline Low & 63 & $8(13)$ & $55(87)$ & 0.001 \\
\hline High & 36 & $15(42)$ & $21(58)$ & \\
\hline \multicolumn{5}{|l|}{$\mathrm{Bcl}-2$} \\
\hline Low & 58 & $5(9)$ & $53(91)$ & $<0.001$ \\
\hline High & 41 & $18(44)$ & $23(56)$ & \\
\hline \multicolumn{5}{|l|}{$P X N / B c l-2$} \\
\hline Low/low & 39 & $3(8)$ & $36(92)$ & $<0.001$ \\
\hline High/low & 19 & $2(11)$ & $17(89)$ & \\
\hline Low/high & 16 & $3(19)$ & $13(81)$ & \\
\hline High/high & 25 & $15(60)$ & $10(40)$ & \\
\hline \multicolumn{5}{|c|}{$p P X N-S 272 / B c l-2$} \\
\hline Low/low & 43 & $3(8)$ & $36(92)$ & $<0.001$ \\
\hline High/low & 15 & $2(11)$ & $17(89)$ & \\
\hline Low/high & 20 & $3(19)$ & $13(81)$ & \\
\hline High/high & 21 & $13(62)$ & $8(38)$ & \\
\hline
\end{tabular}

The responses were categorized as follows: complete response (CR): a complete disappearance of all the tumors; Partial response (PR): a decrease in size or number of the tumor lesions by $50 \%$ or more; Progressive disease (PD): at least $25 \%$ increase in size or number of the tumor lesions; and Stable Disease (SD): neither sufficient shrinkage to qualify for PR nor sufficient increase to qualify for PD. Therefore, a favorable response (CR and $P R)$ is a decrease in tumor size of least $50 \%$ or more

Some studies showed either no correlation between $\mathrm{Bcl}-2$ expression and survival, or that overexpression of $\mathrm{Bcl}-2$ correlated with an unfavorable outcome in colorectal cancer patients. ${ }^{28-31}$ The clinical utility is not yet verified. In this study, we provide novel evidence to demonstrate that the interaction of $\mathrm{PXN}$ with $\mathrm{Bcl}-2$ promotes $\mathrm{Bcl}-2$ protein stability via phosphorylation of PXN at S272 and Bcl-2 at S87 by pPXNY31/Y118-mediated PAK1 and ERK activation, and this Bcl-2 protein stability confers 5 -FU resistance in cells and xenograft tumors. In the study population, patients with high PXN/high $\mathrm{Bcl}-2$ or high pPXN-S272/high Bcl-2 tumors exhibited poorer outcome than those with high PXN, high pPXN-S272 or high Bcl-2 alone tumors (Supplementary Table 1). Therefore, we suggest that PXN-mediated Bcl-2 expression may contribute to tumor malignancy and poor outcome in colorectal cancer, especially in patients receiving 5-FU-based chemotherapy.

Among patients, pPXN-S272 expression was positively correlated with PXN expression. PXN and pPXN-S272 expression were more commonly observed in late-stage tumors (Dukes $C$ and D) than in early-stage tumors (Dukes $A$ and $B$ ) (Table 1). In addition, the highest unfavorable response rate of 5-FU-based chemotherapy and poorer outcomes were seen in patients with high $\mathrm{PXN} /$ high $\mathrm{Bcl}-2$ or high pPXN-S272/ high Bcl-2 tumors, who were all from Dukes $C$ and $D$ patients in comparison with the other three subgroups, whose tumors were only $25-73 \%$ of Dukes $C$ and
D (data not shown). To explore whether Bcl-2 protein stability through PXN interaction with Bcl-2 not only confers drug resistance but also promotes tumor malignancy, cell invasion capability was evaluated via a Matrigel Boyden chamber assay in WT PXN-overexpressing HT29 cells with or without IPA-3 treatment, and HT29 cells with mutant PXN-S272A transfection. As shown in Supplementary Figure 8, the invasion capability was significantly suppressed by IPA-3 in WT PXN-overexpressing HT29 cells. The invasiveness was also reduced in HT29 cells with mutant PXN-S272A transfection. However, the invasion capability can be restored by MG-132 treatment in WT PXN-overexpressing HT29 cells with IPA-3 treatment and in HT29 cells with mutant PXN-S272A transfection. The change of invasion capability was consistent with $\mathrm{Bcl}-2$ expression levels modulated by IPA-3 and mutant PXN-S272A in HT29 cells. These results seem to show why colorectal cancer patients with high PXN or high pPXN-S272 combined with high Bcl-2 tumors had the worst outcome as compared with patients with tumors in the other three categories. We thus suggest that $\mathrm{Bcl}-2$ protein stability as a result of $\mathrm{PXN}$ interaction with $\mathrm{Bcl}-2$ may have a crucial role in drug resistance and poor outcomes in colorectal cancer patients with Dukes $\mathrm{C}$ and $\mathrm{D}$ tumors.

In summary, we provided the evidence that $\mathrm{Bcl}-2$ protein stability via PXN interaction with $\mathrm{Bcl}-2$ has a crucial role in 5 -FU resistance and poor outcomes in colorectal cancer. Moreover, 5-FU resistance can be conquered by Src inhibitors (Dasatinib), PAK1 inhibitors (IPA-3) or Bcl-2 antagonists (ABT-199) in cells and xenograft tumors. Therefore, we suggest that Src inhibitor or Bcl-2 antagonist may potentially conquer the resistance of 5-FU-based chemotherapy and, in turn, improve the outcome of colorectal cancer patients with high PXN/ high Bcl-2 or high pPXN-S272/high Bcl-2 tumors.

\section{Materials and Methods}

Study subjects. The study included 99 patients who underwent resection at the Department of Surgery at the Chung Shan Medical University Hospital (CSMUH) in Taichung, Taiwan, between June 1994 and December 2006. The demographics and clinical features of the 99 colorectal cancer patients are shown in Supplementary Table 2. The median follow-up time was 986 days (ranging from 21 to 2572 days) and the end of the follow-up period was December 2007. The IRB protocol CS07159 was approved by CSMUH.

Tumor response to 5-FU-based chemotherapy. Ninety-nine patients treated with 5-FU-based chemotherapy were enrolled in the study. The drug for chemotherapy is listed in Supplementary Table 3. The treatment methods and duration of treatment was 5-FU-based therapy on day 1 every 3 weeks. The oncologists could administer the chemotherapy locally, but patients were required to return to the participating institution for evaluation after every two cycles. In the absence of PD, patients received at least four cycles of 5-FU-based chemotherapy. Colony-stimulating factors were administered at the treating physician's discretion. Dose delays and reductions were within standards for these regimens. After two and four cycles of chemotherapy, response was characterized by the four-category ordinal variables taking on the values PD, SD, PR or CR. The responses were categorized as follows: CR: a complete disappearance of all the tumors; PR: a decrease in size or number of the tumor lesions by $50 \%$ or more; PD: at least $25 \%$ increase in size or number of the tumor lesions; and SD: neither sufficient shrinkage to qualify for PR nor sufficient increase to qualify for PD. Therefore, a favorable response (CR and $\mathrm{PR}$ ) is a decrease in tumor size of least $50 \%$ or more.

Cell lines. CCM3 cells was kindly provided by Dr. Wun-Shaing Wayne Chang (National Institute of Cancer Research, National Health Research Institutes, Miaoli, Taiwan). All other cells were obtained from the American Type Culture Collection 
(ATCC, Manassas, VA, USA) and cultured as described. Cells were cultured and stored according to the supplier's instructions and used at passages 5-20. Once resuscitated, cell lines are routinely authenticated (once every 6 months, cells were last tested in December 2011) through cell morphology monitoring, growth curve analysis, species verification by isoenzymology and karyotyping, identity verification using short tandem repeat profiling analysis, and contamination checks.

Plasmid constructs and reagents. The PXN-GFP overexpression plasmid constructed into PAcGFP1-N1 vector was kindly provided by Dr. Salgia (The University of Chicago, Chicago, IL, USA). ${ }^{32}$ Mutant PXN-GFP (tyrosine 31/118 changed to phenylalanine: $\mathrm{Y} 31 / 118 F$, serine 272 changed to alanine: S272A and LD4 domain deletion: $\Delta$ LD4) and Bcl-2-Flag (serine 87 changed to alanine: S87A and serine 87 changed to glutamic acid: S87E) expression constructs containing multiple-point mutations were constructed by the QuickChange site-directed mutagenesis system (Stratagene, La Jolla, CA, USA). The Bcl-2-Flag overexpression plasmid constructed into pCMV-Tag2B vector was purchased from Addgene (Addgene Company, Cambridge, MA, USA). shBcl-2 (\#1 TRCN0000040071; \#2 TRCN0000010303), shBcl-XL (\#1 TRCN0000033499; \#2 TRCN0000033500) and shPXN (\#1 TRCN0000123137; \#2 TRCN0000123138) was purchased from National RNAi Core Facility, Academia Sinica, Taipei, Taiwan. Different concentrations of expression plasmids were transiently transfected into lung cancer cells $\left(1 \times 10^{6}\right)$ using the Turbofect reagent (Formentas, Glen Burnie, MD, USA). After $48 \mathrm{~h}$, the cells were harvested and whole-cell extracts were assayed in subsequent experiments.

Chemicals and antibodies. Dasatinib was obtained from LC Laboratories (Woburn, MA, USA). 5-FU and IPA-3 were acquired from Sigma Chemical (St. Louis, MO, USA) unless otherwise indicated. ABT-199 was obtained from ActiveBiochem (Maplewood, NJ, USA). All other chemicals anti-cleavage caspase 3, anti-total ERK and anti-p-ERK antibodies were purchased from Cell Signaling (Danvers, MA, USA). Anti-PXN antibody was obtained from NeoMarker (Fremont, CA, USA). Anti-phosphoY31-PXN (pPXN-Y31) anti-PAK1, anti-phosphoSer144PAK1 (p-PAK1) and anti-Bcl-2 was obtained from Genetex (Irvine, CA, USA). AntiphosphoS272-PXN (pPXN-S272) was purchased from ECM bioscience (Versailles, KY, USA). All other antibodies were purchased from Santa Cruz Biotechnology (Dallas, TX, USA).

Real-time quantitative RT-PCR analysis. Total RNA extraction and reverse transcriptase reaction were described previously. ${ }^{8}$ The following primer sequences were used for amplification of the Bcl-2 gene: the forward primer, 5'-CTGTGGATGACTGAGTACC-3' and the reverse primer, 5'-CAGCCAGG AGAAATCAAAC-3'.

Western blotting. The cells were lysed with lysis buffer containing $0.5 \%$ NP-40, $50 \mathrm{mM}$ Tris-Cl (pH 7.5), $1 \mathrm{mM}$ ethylenediaminetetraacetic acid (EDTA) and protease inhibitor cocktail (Roche, Indianapolis, IN, USA). After $3 \mathrm{~min}$ of lysis, the cell debris was removed by centrifugation, and the protein concentration was determined using a Bradford protein assay kit (Bio-Rad, Hercules, CA, USA). Equal amounts of protein were separated onto sodium dodecyl sulfate-polyacrylamide gel electrophoresis (SDS-PAGE) gels and then transferred from the gel onto a polyvinylidene difluoride membrane (PerkinElmer, Norwalk, CT, USA). After blocking, the membranes were reacted with antibody at $4^{\circ} \mathrm{C}$ overnight, followed by incubation with horseradish peroxidase-conjugated secondary antibody for $1 \mathrm{~h}$. The blots were observed using an enhanced chemiluminescence kit (PerkinElmer).

IP analysis. For the IP experiments, cells transfected with plasmids were harvested and cell lysates were prepared using IP lysis buffer $(20 \mathrm{mmol} / \mathrm{I}$ Tris- $\mathrm{Cl}(\mathrm{pH}$ 7.5), $150 \mathrm{mmol} / / \mathrm{NaCl}, 10 \%$ glycerol, and $1 \%$ Triton X-100). Cell extracts (1.5 mg) were incubated with $40 \mu \mathrm{l}$ of anti-antibody-agarose affinity gel (Millipore, Billerica, MA, USA). After extensive washing with IP lysis buffer, the immunoprecipitated proteins were analyzed by immunoblotting using specific antibodies. ${ }^{33}$

Immunohistochemical analysis. IHC was used to detect PXN, pPXNS272 and Bcl-2 expression. Specimens were formalin fixed and paraffin embedded. Briefly, $3 \mu \mathrm{m}$ sections were cut, mounted on glass and dried overnight at $37^{\circ} \mathrm{C}$. All sections were then deparaffinized in xylene, rehydrated through alcohol and washed in phosphate-buffered saline. This buffer was used for all subsequent washes. Sections for PXN, pPXN-S272 and Bcl-2 detection were heated in a microwave oven twice for $5 \mathrm{~min}$ in citrate buffer ( $\mathrm{pH} \mathrm{6.0).} \mathrm{Anti-PXN,} \mathrm{pPXN-S272} \mathrm{and} \mathrm{Bcl-2}$ antibody was used as the primary antibody and the incubation time was $60 \mathrm{~min}$ at room temperature followed by a conventional streptavidin peroxidase method (LSAB Kit K675, DAKO, Carpinteria, CA, USA). Signals were developed with 3, $3^{\prime}$-diaminobenzidine for $5 \mathrm{~min}$ and counter stained with hematoxylin. Negative controls were obtained by leaving out the primary antibody. The intensities of signals were evaluated independently by three observers. Immunostaining scores were defined as the cell staining intensity $(0=$ nil; $1=$ weak; $2=$ moderate; and $3=$ strong) multiplied by the percentage of labeled cells $(0-100 \%)$, leading to scores from 0 to 300. A score over 150 was rated as 'high' immunostaining, whereas a score $<150$ was rated as 'low'.

MTT cytotoxicity assay. The cell lines were cultured in a humidified incubator containing $95 \%$ air and $5 \% \mathrm{CO}_{2}$ at $37^{\circ} \mathrm{C}$ in 96-well flat-bottomed microtiter plates containing RPMI and DMEM supplemented with $10 \%$ heatinactivated fetal bovine serum (FBS), $100 \mathrm{U} / \mathrm{ml}$ penicillin and $100 \mathrm{U} / \mathrm{ml}$ streptomycin. Before 5-FU treatment, the cells in the exponential growth phase were pretreated with overexpression and knockdown plasmids for $24 \mathrm{~h}$. After $48 \mathrm{~h}$ of incubation, the in vitro cytotoxic effects of these treatments were determined by MTT assay (at $570 \mathrm{~nm})$ and the cell viability was expressed as a percentage of the control (untreated) cells (\% of control). ${ }^{8}$

Annexin-V staining. The cells were collected by trypsinization and centrifugation at $1000 \mathrm{~g}$ for $5 \mathrm{~min}$. Following resuspension in binding buffer (10 mM HEPES- $\mathrm{NaOH}, 140 \mathrm{mM} \mathrm{NaCl}, 2.5 \mathrm{mM} \mathrm{CaCl}$ ) at a final cell density of $1-2 \times 10^{6} \mathrm{celll} / \mathrm{ml}, 100 \mu$ l of a single-cell suspension $\left(1-2 \times 10^{5}\right.$ cells) was incubated with $5 \mu \mathrm{l}$ Annexin V-FITC and $5 \mu \mathrm{lPI}$ for $15 \mathrm{~min}$ at room temperature in the dark. After the addition of $400 \mu \mathrm{l}$ of binding buffer, the samples were analyzed using a BD FACS Calibur flow cytometer (BD Biosciences, San Jose, CA, USA) within $1 \mathrm{~h}$. For each sample, 10000 events were counted.

Invasion assay. A Boyden chamber with a pore size of $8 \mu \mathrm{m}$ was used for the in vitro cell invasion assay. Cells $\left(1 \times 10^{4}\right)$ in $0.5 \%$ serum containing culture medium (HyClone, Ogden, UT, USA) were plated in the upper chamber and 10\% FBS was added to culture medium in the lower chamber as a chemoattractant. The upper side of the filter was covered with $0.2 \%$ Matrigel (Collaborative Research, Boston, MA, USA) diluted in RPMI-1640. After $16 \mathrm{~h}$, cells on the upper side of the filter were removed and cells that adhered to the underside of membrane were fixed in $95 \%$ ethanol and stained with $10 \%$ Giemsa dye. The number of invasive cells was counted. Ten contiguous fields of each sample were examined to obtain a representative number of cells that invaded across the membrane.

In vivo animal model experiments. For therapeutic experiments in tumor growth, tumor cells were injected subcutaneously into the back of 4- to 5-week-old female Balb/c nude mice. Xenograft size was measured every 3 days and tumor volume was determined as $\left(\right.$ length $\times$ width $\left.^{2}\right) / 2$. When the tumors grew to $150 \mathrm{~mm}^{3}$, the mice were randomized to the indicated groups: vehicle (DMSO), $5-\mathrm{FU}(5 \mathrm{mg} / \mathrm{kg} /$ 3 days), Dasatinib (5 mg/kg/3 days), IPA-3 (5 mg/kg/3 days) ABT-199 (5 mg/kg/ 3 days) and combined each two drugs. Drugs were administrated by intraperitoneal injection.

Statistical analysis. Statistical analysis was performed using the SPSS statistical software program (Version 18.0; SPSS Inc., Chicago, IL, USA). The association between tumor response and PXN protein expression was analyzed by the $\chi^{2}$ test. Multivariate Cox regression analysis was performed to determine OS and relapse-free survival. The analysis was stratified for all known variables (age, gender, smoking status, tumor type and tumor stage) and protein expression.

\section{Conflict of Interest}

The authors declare no conflict of interest.

Acknowledgements. This work was jointly supported by grants from the National Science Council (103-2320-B-038-036-MY2) and the National Health Research Institute (NHRI-EX103-10328BI) of Taiwan, ROC.

1. Tarvera T. Cancer Facts \& Figures 2012. American Cancer Society (ACS). J Consum Health Internet 2012; 16: 2.

2. Cause of death statistics in Taiwan. In: Department of Health EY, ROC (TAIWAN), editor. 2012. 
3. Schmoll HJ, Buchele T, Grothey A, Dempke W. Where do we stand with 5-fluorouracil? Semin Oncol 1999; 26: 589-605.

4. Wang Y, Jatkoe T, Zhang Y, Mutch MG, Talantov D, Jiang J et al. Gene expression profiles and molecular markers to predict recurrence of Dukes' B colon cancer. J Clin Oncol 2004; 22: 1564-1571.

5. Willett CG, Czito BG, Bendell JC. Radiation therapy in stage II and III rectal cancer. Clin Cancer Res 2007; 13(22 Pt 2): 6903s-6908s.

6. Chen DL, Wang DS, Wu WJ, Zeng ZL, Luo HY, Qu MZ et al. Overexpression of paxillin induced by miR-137 suppression promotes tumor progression and metastasis in colorectal cancer. Carcinogenesis 2013; 34: 803-811.

7. Yin $\mathrm{H}$, Zhang $\mathrm{Q}$, Wang $\mathrm{X}$, Li T, Wan $\mathrm{Y}$, Liu $\mathrm{Y}$ et al. Role of paxillin in colorectal carcinoma and its relationship to clinicopathological features. Chin Med J 2014; 127: 423-429.

8. Wu DW, Wu TC, Wu JY, Cheng YW, Chen YC, Lee MC et al. Phosphorylation of paxillin confers cisplatin resistance in non-small cell lung cancer via activating ERK-mediated Bcl-2 expression. Oncogene 2013; 33: 4385-4395

9. Sorenson $\mathrm{CM}$. Interaction of $\mathrm{bcl}-2$ with paxillin through its $\mathrm{BH} 4$ domain is important during ureteric bud branching. J Biol Chem 2004; 279: 11368-11374.

10. Nayal A, Webb DJ, Brown CM, Schaefer EM, Vicente-Manzanares M, Horwitz AR. Paxillin phosphorylation at Ser273 localizes a GIT1-PIX-PAK complex and regulates adhesion and protrusion dynamics. J Cell Biol 2006; 173: 587-589.

11. Breitschopf K, Haendeler J, Malchow P, Zeiher AM, Dimmeler S. Posttranslational modification of $\mathrm{Bcl}-2$ facilitates its proteasome-dependent degradation: molecular characterization of the involved signaling pathway. Mol Cell Biol 2000; 20: 1886-1896.

12. Andre T, Boni C, Mounedji-Boudiaf L, Navarro M, Tabernero J, Hickish T et al. Oxaliplatin, fluorouracil, and leucovorin as adjuvant treatment for colon cancer. N Engl J Med 2004; 350 : 2343-2351

13. Souers AJ, Leverson JD, Boghaert ER, Ackler SL, Catron ND, Chen J et al. ABT-199, a potent and selective BCL-2 inhibitor, achieves antitumor activity while sparing platelets. Nat Med 2013; 19: 202-208.

14. Nie J, Liu L, Zheng W, Chen L, Wu X, Xu Y et al. microRNA-365, down-regulated in colon cancer, inhibits cell cycle progression and promotes apoptosis of colon cancer cells by probably targeting cyclin D1 and Bcl-2. Carcinogenesis 2012; 33: 220-225.

15. Nita ME, Nagawa H, Tominaga O, Tsuno N, Fujii S, Sasaki S et al. 5-Fluorouracil induces apoptosis in human colon cancer cell lines with modulation of Bcl-2 family proteins. Br J Cancer 1998; 78: 986-992.

16. Zhu H, Guo W, Zhang L, Davis JJ, Teraishi F, Wu S et al. Bcl-XL small interfering RNA suppresses the proliferation of 5 -fluorouracil-resistant human colon cancer cells. Mol Cancer Ther 2005; 4: 451-456.

17. Wang C, Youle RJ. Predominant requirement of Bax for apoptosis in HCT116 cells is determined by Mcl-1's inhibitory effect on Bak. Oncogene 2012; 31: 3177-3189.

18. Yang J, Liu X, Bhalla K, Kim CN, Ibrado AM, Cai J et al. Prevention of apoptosis by Bcl-2 release of cytochrome c from mitochondria blocked. Science 1997; 275: 1129-1132.
19. Yeh JJ, Routh ED, Rubinas T, Peacock J, Martin TD, Shen XJ et al. KRAS/BRAF mutation status and ERK1/2 activation as biomarkers for MEK1/2 inhibitor therapy in colorectal cancer. Mol Cancer Ther 2009; 8: 834-843.

20. Friday BB, Adjei AA. Advances in targeting the Ras/Raf/MEK/Erk mitogen-activated protein kinase cascade with MEK inhibitors for cancer therapy. Clin Cancer Res 2008; 14: 342-346.

21. Matallanas D, Romano D, Al-Mulla F, O'Neill E, Al-Ali W, Crespo P et al. Mutant K-Ras activation of the proapoptotic MST2 pathway is antagonized by wild-type K-Ras. Mol Cell 2011; 44: 893-906

22. Mao M, Tian F, Mariadason JM, Tsao CC, Lemos Jr R, Dayyani F et al. Resistance to BRAF inhibition in BRAF-mutant colon cancer can be overcome with PI3K inhibition or demethylating agents. Clin Cancer Res 2013; 19: 657-667.

23. Wickenden JA, Jin H, Johnson M, Gillings AS, Newson C, Austin M et al. Colorectal cancer cells with the BRAF(V600E) mutation are addicted to the ERK1/2 pathway for growth factorindependent survival and repression of BIM. Oncogene 2008; 27: 7150-7161.

24. Wee S, Jagani Z, Xiang KX, Loo A, Dorsch M, Yao YM et al. PI3K pathway activation mediates resistance to MEK inhibitors in KRAS mutant cancers. Cancer Res 2009; 69: 4286-4293.

25. She QB, Halilovic E, Ye Q, Zhen W, Shirasawa S, Sasazuki T et al. 4E-BP1 is a key effector of the oncogenic activation of the AKT and ERK signaling pathways that integrates their function in tumors. Cancer Cell 2010; 18: 39-51.

26. Bielecki A, Roberts J, Mehta R, Raju J. Estrogen receptor-beta mediates the inhibition of DLD-1 human colon adenocarcinoma cells by soy isoflavones. Nutr Cancer 2011; 63: 139-150.

27. Kreeger PK, Mandhana R, Alford SK, Haigis KM, Lauffenburger DA. RAS mutations affect tumor necrosis factor-induced apoptosis in colon carcinoma cells via ERK-modulatory negative and positive feedback circuits along with non-ERK pathway effects. Cancer Res 2009; 69: 8191-8199

28. Manne U, Weiss HL, Grizzle WE. Bcl-2 expression is associated with improved prognosis in patients with distal colorectal adenocarcinomas. Int J Cancer 2000; 89: 423-430.

29. Bosari S, Moneghini L, Graziani D, Lee AK, Murray JJ, Coggi G et al. bcl-2 oncoprotein in colorectal hyperplastic polyps, adenomas, and adenocarcinomas. Hum Pathol 1995; 26 . 534-540.

30. Bhatavdekar JM, Patel DD, Ghosh N, Chikhlikar PR, Trivedi TI, Suthar TP et al. Coexpression of Bcl-2, C-Myc, and p53 oncoproteins as prognostic discriminants in patients with colorectal carcinoma. Dis Colon Rectum 1997; 40: 785-790.

31. Sinicrope FA, Hart J, Michelassi F, Lee JJ. Prognostic value of bcl-2 oncoprotein expression in stage II colon carcinoma. Clin Cancer Res 1995; 1: 1103-1110.

32. Jagadeeswaran R, Surawska $H$, Krishnaswamy $S$, Janamanchi V, Mackinnon AC, Seiwert TY et al. Paxillin is a target for somatic mutations in lung cancer: implications for cell growth and invasion. Cancer Res 2008; 68: 132-142.

33. Wu DW, Lee MC, Wang J, Chen CY, Cheng YW, Lee H. DDX3 loss by p53 inactivation promotes tumor malignancy via the MDM2/Slug/E-cadherin pathway and poor patient outcome in non-small-cell lung cancer. Oncogene 2013; 33: 1515-1526.

Supplementary Information accompanies this paper on Cell Death and Differentiation website (http://www.nature.com/cdd) 